\title{
A Pós-graduação da Medicina Veterinária na Universidade de São Paulo: correspondência elucidativa*
}

The post-graduation in Veterinary Medicine at the University of São
Paulo, Brazil: elucidative correspondence El posgrado en Medicina Veterinaria de la Universidad de São Paulo,
Brasil: correspondencia explicativa

\section{Senhor Editor,}

Em mensagem enviada aos docentès da Faculdade de Medicina Veterinária e Zootecnia da Universidade de São Paulo abordo a comemoração, em 2004, dos "70 Anos de Criação e Implantação da Universidade de São Paulo" e as festividades, paralelas, que a Pró-Reitoria de Pós-graduação promoveu sobre os "35 Anos da Pós-graduação na USP". Argumento que as comemorações da Pós-graduação foram promovidas e divulgadas com registro errado de data, pois os primeiros títulos de Mestre em Medicina Veterinária obtidos por colegas do Estado de São Paulo foram na Faculdade de Medicina Veterinária da USP no período de 1965 a 1970.

\footnotetext{
*Correspondência enviada aos Docentes da Faculdade de Medicina Veterinária e Zootecnia da Universidade de São Paulo, contestando a existência de apenas 35 anos de Pós-graduação na Universidade de São Paulo.
} 


\section{Aos Prezados Colegas e Estimados Amigos,}

Pela mensagem que recebi, como receberam os demais Docentes da Faculdade de Medicina Veterinária e Zootecnia da Universidade de São Paulo, São Paulo, SP, (FMVZ/USP) ressaltando as festividades de "35 Anos da Pós-graduação" em nossa Universidade de São Paulo, demonstrou-se um dentre dois fatos: a Administração da Universidade, simplesmente não considerou as realizações passadas de suas unidades de ensino participantes da comunidade universitária paulista desde a sua criação e implantação em 1934, revelando desconhecimento da história do ensino - em vários níveis - que suas faculdades e cursos ofereceram (e talvez ofereçam), ou fazem como recomendam suas Bibliotecas, desprezar o antigo, sem registrar a história de uma gloriosa evolução.

Eu não concordo com a afirmação festiva dos "35 Anos da Pós-graduação na Universidade de São Paulo" e, apresento as razões.

1. Há 37 anos (em 9 de novembro de 1967 coincidentemente na data em que completava 35 anos de idade e 9 anos como docente da Faculdade de Medicina Veterinária da Universidade de São Paulo - FMV/USP) recebia meu Diploma de Mestre dessa unidade de ensino superior; diploma assinado pelo ilustre diretor desta casa, Professor Doutor Orlando Marques de Paiva, que na década de 70 seria o Magnífico Reitor da Universidade de São Paulo (na oportunidade, obedecendo aos preceitos da Portaria GR-172/65, apresentei dissertação de mestrado aprovada pelos Professores Dr. Romeu Diniz Lamounier, da FMV/USP, Dr. Leônidas Machado Magalhães, Professor Catedrático da Universidade Federal de Minais Gerais e Dr. Eurípides Malavolta, Professor Catedrático e, na oportunidade, Diretor da Escola Superior de Agronomia da USP).

2. Há 38 anos (em 5 de julho de 1966) tinha recebido meu certificado de conclusão, nos termos do regulamento em vigor, com aprovação no Curso de Pós-graduação em "Reprodução Animal", documento também assinado pelo Diretor da FMV/USP, o Professor Doutor Orlando Marques de Paiva, apresentando, para tanto, o trabalho de conclusão de curso "Vantagens e desvantagens da enucleação do corpo lúteo na vaca", monografia aprovada pela comissão julgadora formada pelos Professores Doutores Ernesto Antonio Matera, Professor Catedrático da FMV/USP e coordenador do curso, Romeu Diniz Lamounier da FMV/USP e Eberhard Grunert, professor universitário da Escola Superior de Veterinária de Hannover da República Federal da Alemanha, que viria a ser meu julgador no Concurso para Professor Titular do Departamento de Patologia e Clínica Médicas da FMVZ/USP, realizado em 1983.

3. Há 36 anos, nos meses de junho e julho de 1968, a convite do Professor Doutor Ernesto Antonio Matera, que coordenava o curso de pós-graduação em "Cirurgia Bovina" (o segundo curso de pósgraduação da FMV/USP que atribuiu diplomas de Mestre em Medicina Veterinária) e, por indicação do Professor Doutor Romeu Diniz Lamounier, ministrei aulas magistrais e práticas nesse curso de pós-graduação promovido pela Faculdade de Medicina Veterinária da Universidade de São Paulo, obedecendo às normas e regulamentações dessa instituição; além do mais, participei de bancas julgadoras das monografias de conclusão de curso.

4. A memória sobre os acontecimentos relevantes das unidades de ensino superior das universidades, de modo geral, não é adequadamente cultuada pelos acadêmicos que, na medida do possível, procuram destacar e rememorar as atividades, das quais participaram diretamente. Recentemente, a FMVZ/USP, comemorou os supostos 25 anos da pós-graduação como Programas Formais desses Cursos, na Universidade de São Paulo, como imposto pela Coordenação de Aperfeiçoamento de Pessoal de Ensino Superior (CAPES). Porém, nessa excelente publicação, comemorativa do evento foram esquecidos por seus Coordenadores os esforços realizados pelos pioneiros professores dessa Faculdade de Medicina Veterinária. Justamente, aqueles que nos salvaram, dos prepotentes 
desígnios da Universidade, que pela Resolução ou Portaria $\mathrm{n}^{2} 68$ (se não me falha a memória) ameaçava os assistentes/instrutores com sumária dispensa, caso não comprovassem, em determinado período, conclusão de curso de pós-graduação (que não existia na USP). Além disso, é fato a se destacar na FMVZ/USP, a freqüência de solicitações da Administração a Docentes e/ou aos Departamentos sobre fatos antigos; bem estabelecidos e divulgados por publicações acadêmicas ou de comissões da instituição, porém a Administração e/ou os setores responsáveis não conservaram ou registraram os eventos. Para caracterizar: recentemente, o Coordenador de um Programa de Pósgraduação solicitou informação sobre quem seria o responsável por determinada disciplina do elenco aprovado e incluído em avaliação da CAPES, mas que havia sido desativada. $\mathrm{O}$ esclarecimento, foi surpreendente ao se descobrir que o responsável pela disciplina fora, justamente, o mencionado Coordenador que fizera o questionamento (nem ele tinha a memória de seu Programa de Pósgraduação ou das disciplinas das quais fora responsável), mesmo tendo sido o apresentador do questionamento. Porém, a maior surpresa foi saber que a Biblioteca e a Administração da PósGraduação na FMVZ/USP não tinham em seu acervo a publicação que, com tanto esforço e dedicação, a Direção da FMVZ publicara como informativo das atividades dessa Unidade de Ensino Superior.

5. Finalizando, poder-se-ia dizer que "felizmente isso não ocorre somente na FMVZ", pois se observa o fato também na Universidade; sobre isso já me pronunciei, lamentando o pequeno destaque que foi dado no "Jornal da USP" aos Magníficos Reitores que atuaram como Professores do Curso de Medicina Veterinária da USP, particularmente por não corrigirem a homenagem feita na deno- minação da Avenida Professor Gabriel Sylvestre Teixeira de Carvalho, que os antigos discentes da Faculdade de Medicina Veterinária chamavam, carinhosamente de "Tio Bié".* A avenida, com o fechamento do portão de saída da USP (próximo ao Grupo Escolar), transformou-se simplesmente no "Beco do Bié" (que atualmente serve apenas para uma entrada lateral da FMVZ/USP, conduzindo os estudantes e criadores ao mais ativo centro de ensino, pesquisa e atendimento de animais ruminantes de nosso país - o Centro de Pesquisa e Diagnóstico de Enfermidades de Ruminantes (CPDER), e Hospital de Bovinos - instalados e implantados com auxílio financeiro recebido da Fundação de Amparo à Pesquisa do Estado de São Paulo (FAPESP). No entanto, o que me chama a atenção em relação à denominação desta avenida e que julgo falta de consideração ou, no mínimo, falta de atenção administrativa da USP, é ver - sem que alguém reclame ou corrija - a exuberante placa, apresentando de forma errônea a denominação da avenida "AV. PROF. GABRIEL S. F. DE CARVALHO”).

Posto isso, reafirmo minhas convicções de que o ensino da pós-graduação nesta unidade de ensino, responsável pelo curso de Medicina Veterinária na Universidade de São Paulo, iniciouse há 39/38 anos (1965-1966). E faço isso imaginando que, a Pró-Reitoria de Pós-graduação possa querer dar a homenagem do início deste ciclo do ensino superior à outra unidade, considerada de "vanguarda" na Universidade.

Em manifestações anteriores propugnei para que na história do Ensino da Medicina Veterinária, no Estado de São Paulo não se considerasse seu início apenas a partir de 1934, época da criação da Universidade de São Paulo - sendo a Faculdade de Medicina Veterinária uma de suas Unidades Funda-

\footnotetext{
*O apelido do Magnífico ex-Reitor Prof. Dr. Gabriel Sylvestre Teixeira de Carvalho - BIÉ devia-se ao fato de na FMV/USP, na década de 50 do século passado, trabalharem na área de atuação do Professor Gabriel dois sobrinhos do ilustre Mestre (o Professor Doutor Paulo de Carvalho Pereira, Livre Docente da Cátedra de Patologia e Clínica Médicas - $2^{\mathrm{a}}$ cadeira, e o Prof. Dr. Maugé Gabriel de Carvalho, Livre Docente da Cátedra de Farmacologia, Terapêutica e Arte de Formular) que assim o tratavam. E, por extensão, os estudantes do saudoso Curso de Veterinária da Rua Pires da Mota, 159, no Bairro da Aclimação, passaram a chamar o Professor Gabriel, simplesmente, de Tio Bié. Ressaltese que, naquela época, a Universidade estava livre do "espírito escolar de curso médio" (para não dizer de "pré-primário") e os professores não eram chamados de Tios.
} 
doras - mas que voltássemos ao passado remoto e às escolas e faculdades que lhe deram origem - a denominada, "Velha Escola ou Velha Faculdade de Veterinária de São Paulo”, que em 1934 incorporou seus novos estudantes ao Curso criado pela Universidade de São Paulo. Assim, a criação do primeiro curso de Medicina Veterinária em São Paulo passou a ser o ano de 1919, configurando-se, no momento, o segundo curso mais antigo de Veterinária em atividade no Brasil, pois o primeiro corresponde ao Curso de Medicina Veterinária da Universidade Federal Rural do Rio de Janeiro (UFRRJ). Em parte, o ano da implantação do Ensino de Veterinária no Estado de São Paulo foi acertado na publicação do catálogo Universidade de São Paulo - 70 Anos (2004) e, no item Faculdade de Medicina Veterinária, destacou: "Criada em 1919 pela Secretaria da Agricultura do Estado de São Paulo a Faculdade de Medicina Veterinária, também é fundadora da Universidade de São Paulo, tendo sido incorporada em 1934." Porém, no capítulo sobre o histórico da USP, nesta mesma publicação, destacou-se uma informação historicamente errada a respeito do Ensino da Veterinária no Brasil, ao afirmar: "Inicialmente, a USP foi formada por sete unidades de ensino já existentes: a Faculdade de Direito, fundada em 1827; a Escola Politécnica em 1883; a Faculdade de Farmácia e Odontologia em 1899; a Faculdade de Medicina Veterinária em 1911..." Não há mais dúvidas, a atual Faculdade de Medicina Veterinária e Zootecnia foi criada pela Lei $\mathrm{n}^{\circ} 1.695$-c de 18 de dezembro de 1919. Quanto ao ensino da Medicina Veterinária no Brasil, em 1910 o Decreto 2.232 criou a Escola de Veterinária do Exército, que iniciou suas atividades em 17 de outubro de 1914, mas paralelamente, em 20 de outubro de 1910, pelo Decreto 8.910 foi criada a Escola Superior de Agricultura e Medicina Veterinária, todavia, apenas em 4 de julho de 1913 iniciou suas atividades (assim, essa Faculdade, hoje ligada à Universidade Federal Rural do Rio de Janeiro (UFRRJ) foi a primeira Unidade de Ensino Superior de nossa profissão, sendo a mais antiga do Brasil e, o Curso da USP, o segundo mais antigo em atividade no País. Assim, o ano de 1911 representa para o ensino da veterinária no Brasil apenas uma expectativa de sua implantação e, em São Paulo, a possibilidade da criação de uma Escola de Medicina
Veterinária passou a existir, somente, após o inicio do ano de 1918.

Em idêntica situação ficará o ensino da Pósgraduação se realmente considerarmos o início da Pós-graduação em Medicina Veterinária na FMV/ FMVZ-USP em 1965, independente de uma decisão errônea ou de dúbia justificação de órgãos administrativos, inadequadamente informados. Dessa maneira, a Faculdade de Medicina Veterinária da Universidade de São Paulo, por direito, seria enaltecida como a promotora e responsável pelo primeiro curso de Pós-graduação - em nível de mestrado - que no Brasil, atribuiu o diploma de Mestre em Medicina Veterinária.

\section{Conclusões}

Inicialmente, ressalto as dúvidas resultantes da interpretação da mensagem divulgando a realização das festividades dos "35 anos da Pós-Graduação na USP". Para tanto, analisei novamente, alguns documentos que nos anos de atividade na USP comprovavam o texto de meus memoriais e de minhas realizações na Faculdade de Medicina Veterinária e na Faculdade de Medicina Veterinária e Zootecnia, ultrapassando todos os degraus da carreira universitária de docentes da USP, de acordo com o Estatuto de 1969.

1. OF.E.1.577/67 - Ofício expedido em 13/XI/1967 pelo Diretor da FMVZ/USP ao Professor Doutor Romeu Diniz Lamounier, Catedrático de Patologia e Clínica Médicas - $2^{\mathrm{a}}$ Cadeira, nos seguintes termos: Tenho a elevada honra de comunicar-lhe que o Conselho Técnico Administrativo em sessão de 9/XI/67 houve por bem conceder o Diploma de Mestre requerido pelo Senhor Eduardo Harry Birgel. Valho-me da oportunidade para renovar-lhe protestos de apreço e consideração.

2. OF.E.1.578/67 - Ofício expedido em 23/XI/67 pelo Diretor da FMV/USP ao senhor Eduardo Harry Birgel, Instrutor da Cadeira de Patologia e Clínica Médicas - $2^{\mathrm{a}}$ Cadeira, nos seguintes termos: Tendo em vista que Vossa Senhoria 
atendeu ao disposto no artigo 14 e parágrafo único da Portaria GR. 172/65 comunico-lhe que o Conselho Técnico Administrativo desta casa, em sessão de 9/XI/67, houve por bem lhe conceder $o$ Diploma de Mestre. Esclareço-lhe que o correspondente diploma lhe será fornecido oportunamente.

3. Pareceres dos Professores Catedráticos: Doutor Romeu Diniz Lamounier (FMV/USP); Doutor Leônidas Machado Magalhães (FMV/UFMG) e Doutor Eurípides Malavolta, da Escola Superior de Agricultura Luiz de Queiroz da USP (ESALQ/ USP), aprovando a Dissertação de Mestrado.

4. Por persistirem ainda dúvidas, consultei a publicação da Universidade de São Paulo - SISTEMA INTEGRADO DE BIBLIOTECAS. Catálogo de teses: 1934-1984. 2. ed. Série III. Ciências biológicas. Parte 2. São Paulo: SIBI, 1987. (ISBN 85.8507C-21-8). No referente à FMVZ/USP, na página 1.000 constatou-se: BIRGEL, EDUARDO HARRY. Contribuição à hematologia de caprinos (Capra hircus), criados no Estado de São Paulo: determinação dos teores de proteínas séricas e plasmáticas em cabras normais; influências de fatores raciais, alimentares e etários. São Paulo, SP, 1967. 54 f. (Dissertação de Mestrado em Patologia e Clínica Médicas)-Faculdade de Medicina Veterinária e Zootecnia da Universidade de São Paulo, São Paulo, 1987. (12754).

Além do mais, nesse Catálogo de Teses constam outras 30 dissertações de mestrado resultantes do Curso de Pós-graduação Animal, dos quais 22 foram apresentadas por docentes da FMVZ/USP. Constam também desse catalogo nove dissertações de mestrado de pós-graduandos do Curso de Cirurgia Bovina ( $2^{\circ}$ curso em nível de pós-graduação oferecido pela FMV/USP), dos quais quatro foram docentes da FMVZ/USP.
Finalmente, apresento a última e maior dúvida, em forma de questão: "Teria a Pós-graduação da Universidade de São Paulo, realmente, apenas 35 anos de existência ou sua Faculdade de Medicina Veterinária foi pioneira, implantando seu ensino de pós-graduação em 1965, com o Curso de Pósgraduação em Reprodução Animal?

Caso a resposta a essa dúvida seja positiva e o ensino em nível de pós-graduação na Universidade de São Paulo tiver somente 35 anos, todos os meus memoriais apresentados em concursos de provimento de cargos ou funções da carreira universitária (Livre Docência, Professor Adjunto, Professor Titular e mesmo a obtenção de meu título de Doctor Medicinae Veterinaria, na Escola Superior de Veterinária em Hannover, - República Federal da Alemanha, atribuído especificamente a médicos veterinários aprovados em cursos de graduação de cinco anos ou a portadores de Título de Mestre) apresentaram erro fundamental por destacar um Título Acadêmico que não possuía, pois a Universidade de São Paulo, naquela época, não apresentava qualquer atividade de ensino de pósgraduação. Da mesma forma, outros 26 docentes da USP que completaram a carreira universitária na FMVZ/USP também não possuiriam tal Título Acadêmico. Isso, apesar de todos nós termos recebido o referido título acadêmico, após completar um curso desse nível na Faculdade de Medicina Veterinária da própria Universidade de São Paulo.

Atenciosamente,

Professor Doutor Eduardo Harry Birgel CRMV-SP 00018

Professor Titular Aposentado da FMVZ/USP Pesquisador Científico Nível IA do CNPq 